The International Journal of Indian Psychology

ISSN 2348-5396 (e) | ISSN: 2349-3429 (p)

Volume 4, Issue 1, No. 79, DIP: 18.01.091/20160401

ISBN: 978-1-365-56745-2

http://www.ijip.in | October-December, 2016

\title{
Learning to Learn
}

\author{
Dr. Nishat Anjum ${ }^{1 *}$
}

\section{ABSTRACT}

Success in the knowledge society depends on the ability to learn. In the context of the knowledge economy, the competence of learning to learn is a basic skill and a quintessential tool for lifelong learning and thus education and training needs to provide the learning environment for the development of this competence for all citizens including persons with fewer opportunities (those with special needs, school dropouts and adult learners) and through different learning environments (formal, non-formal and informal). The EUROPEAN UNION working group on "Key competencies" identified 'Learning to learn' as the ability to pursue and persist in learning. They argued that: "Individuals should be able to organise their own learning, including through effective management of time and information, both individually and in groups. Competence includes awareness of one's learning process and needs, identifying available opportunities, and the ability to handle obstacles in order to learn successfully. It means gaining, processing and assimilating new knowledge and skills as well as seeking and making use of guidance. Learning to learn engages learners to build on prior learning and life experiences in order to use and apply knowledge and skills in a variety of contexts - at home, at work, in education and training”. For all the reasons given above, and for many others, the focus of education is shifting from "teaching" to "learning" today. Teacher's roles are changing from lecturing to "designers of learning methods and environments" (Barr and Tagg 1995, cited in Fink 2003). This paper discusses various steps, challenges, tools \& strategies and barriers in learning to learn.

Keywords: Learning, Competencies, Dropout

Education is effective when it succeeds in promoting the personal growth and development of individuals. The concept of learning-to-learn has been adopted in response to the new challenges and demands due to the educational reforms around the world. Learning-to-learn provides an easy to execute and cost-effective measure for the assessment of factors that have been found relevant for lifelong learning, in the transfer of learning and in the practical constitution of new knowledge. Learning to learn has been defined in several different contexts. The European Commission suggested a single definition of learning to learn (European Commission, 2005):

\footnotetext{
${ }^{1}$ Asst. Professor, Head of the Department, Aligarh College of Education, Aligarh, U.P., India *Responding Author

(C) 2016 N Anjum; licensee IJIP. This is an Open Access Research distributed under the terms of the Creative Commons Attribution License (http://creativecommons.org/licenses/by/2.0), which permits unrestricted use, distribution, and reproduction in any Medium, provided the original work is properly cited.
} 


\section{Learning to Learn}

'Learning to learn' is the ability to pursue and persist in learning. Individuals should be able to organise their own learning, including through effective management of time and information, both individually and in groups. Competence includes awareness of one's learning process and needs, identifying available opportunities, and the ability to handle obstacles in order to learn successfully. It means gaining, processing and assimilating new knowledge and skills as well as seeking and making use of guidance. Learning to learn engages learners to build on prior learning and life experiences in order to use and apply knowledge and skills in a variety of contexts - at home, at work, in education and training. Motivation and confidence are crucial to an individual's competence."

To prepare students for "emerging challenges in the workplace, in a diverse democracy, and in an interconnected world" institutions should place new emphasis on educating students to be "intentional learners" who are purposeful and self-directed, empowered through intellectual and practical skills, informed by knowledge and ways of knowing, and responsible for personal actions and civic values (AACU, 2002). They "take the initiative to diagnose their learning needs, formulate learning goals, identify resources for learning, select an implement learning strategies, and evaluate learning outcomes” (Savin-Baden and Major 2004). Specifically, the AACU report recommends that students should learn to:

- $\quad$ effectively communicate orally, visually, in writing, and in a second language

- $\quad$ understand and employ quantitative and qualitative analysis to solve problems

- $\quad$ interpret and evaluate information from a variety of sources

- $\quad$ understand and work within complex systems and with diverse groups

- $\quad$ demonstrate intellectual agility and the ability to manage change

- $\quad$ transform information into knowledge and knowledge into judgment and action

According to Kolb (1984), the learning cycle begins when the learner interacts with the environment (concrete experience). Sensory information from this experience is integrated and compared with existing knowledge (reflective observation). New models, ideas, and plans for action are created from this information (abstract hypotheses), and finally new action is taken (active testing). The Kolb cycle is consistent with the earlier work of Piaget and others who pointed out that learning have both a concrete (active) and an abstract (intellectual) dimension. Within the brain, knowledge is organized and structured in networks of related concepts. Accordingly, new knowledge must connect to, or build upon a framework of existing knowledge (Zull 2002). Put simply, learning involves building mental models (schema) consisting of new and existing information. The richer the links between new and existing information, the deeper the knowledge and the more readily it can be retrieved and applied in new situations. 


\section{Learning to Learn}

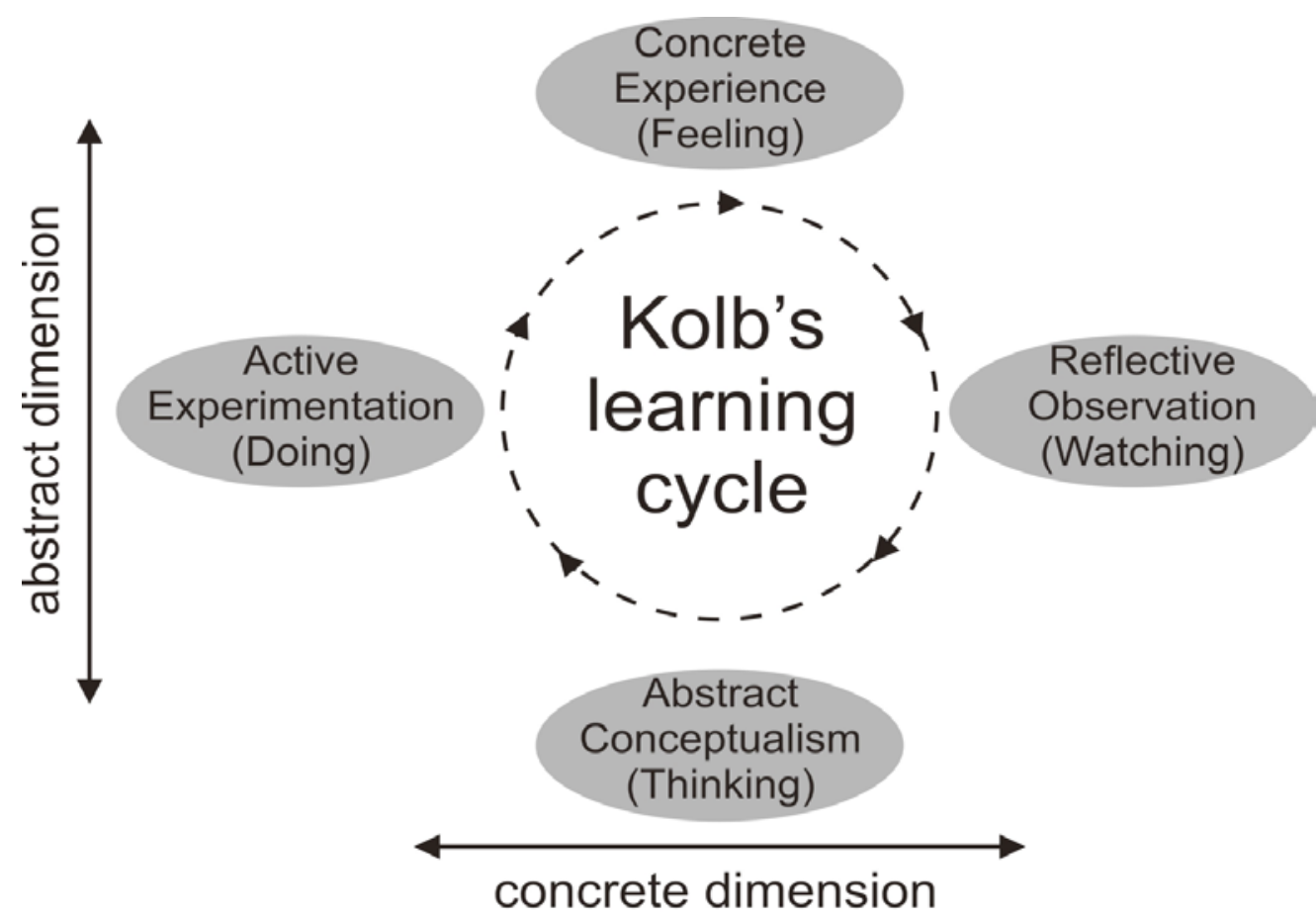

\section{CHALLENGES OF LEARNING TO LEARN}

Learning approaches based on the transmission of known solutions or explicit means of finding solutions from teachers to students cannot prepare students to address complex problems in complex systems. The unique needs of independent learning cause it to be difficult to develop competence due to several factors:

- Because learning to learn is a process it is more abstract than learning known specific facts and procedures. This requires students to generalize and apply perspectives with multiple levels of aggregation.

- Learning to learn can require a change in the student's mental model of learning from a more structured and rigid knowledge base or set of steps to be applied once to a more flexible iterative process (Doyle and Ford, 1998).

- Verifying that independent learning has occurred is difficult because the proper use a flexible set of procedures is less recognizable than many other learning indicators.

- Learning to learn is heavily dependent supporting on conditions which are difficult to provide, assess and facilitate such as safe learning spaces for experimentation.

- Learning to learn often includes questioning and adjusting objectives and measures of those objectives.

Despite these difficulties the challenges of independent learning are not obvious. In fact many complex systems appear deceptively easy to manage (Sterman, 1992). Convincing students of their need for effective independent learning skills is a first step in learning to learn. Therefore

(C) The International Journal of Indian Psychology, ISSN 2348-5396 (e) | ISSN: 2349-3429 (p) | 104 


\section{Learning to Learn}

effectively demonstrating the challenges inherent in designing and managing complex systems and the need for independent learning skills is critical.

\section{STEPS IN LEARNING TO LEARN}

Effective study skills and strategies are the basis of effective learning. They give you an opportunity to approach learning tasks systematically and independently. By always using good study habits -learning to work smarter - you will work like and become a successful student. There isn't one study/learning skill or strategy that works for every person in every situation. Therefore, learning to learn strategies are about learning what you know, learning what you don't know, and learning what to do about it. Learning strategies will:

- Enable you to take more responsibility for your own learning

- Allow you to spend your time effectively and stay on task

- Help you select the best approach(s) for each assignment/task

- Provide you with the knowledge and skills needed to begin, follow-through, and complete assignments/tasks

- Present you with access to a variety of content and reference materials

- Give you the confidence to know when and who to ask for help

\section{Know Yourself}

Begin by honestly assessing the strengths and weaknesses in basic college skills - reading, writing, listening, and mathematics - and study/work habits such as organization, time management, concentration, listening, and note taking. Next, identify the learning style preferences. Many factors affect learning, but consider whether the learning is most effective by reading, by watching, by listening, or by doing. You must also become familiar with your teachers' teaching styles to help you adapt your learning style to the best advantage. In addition, consider when (are you a morning person or a night owl) and where (do you concentrate best in a bright room with noise or in a cozy, quiet corner) you are at your best for learning.

\section{Manage Your Time and Life}

The first step in learning to manage the time - controlling your own life - is to identify what are the goals are and then establish the priorities to help you reach them. Analyze how you are using your time. If time is not spent on your priorities, you must make the necessary adjustments or you won't reach your goals. If school, learning and good grades are a priority, then you must make and follow a schedule that gives a significant amount of time to class and study.

\section{Improve Your Concentration}

As a good student, use your study time more effectively. Learn to keep your attention focused on the task at hand - concentrate. When you are in class or ready to study, give it your full attention. And remember, how well you learn something, not how fast you learn it, is critical factor in remembering. You must "get” something before you can "forget” it.

(c) The International Journal of Indian Psychology, ISSN 2348-5396 (e)| ISSN: 2349-3429 (p) | 105 


\section{Learning to Learn}

\section{Know What Study Means \& How to Do It}

Learning takes more than just going to class and doing homework. It is really a four-part cycle:

$$
\text { Preview } \rightarrow \text { class } \rightarrow \text { review } \rightarrow \text { study. }
$$

When you establish learning - cycle routine you will be able to learn more in less time with less stress.

\section{Develop a Thinker's Vocabulary}

Ability to understand the meaning of the words and to select the right one(s) to communicate the ideas, information, and feelings is very important to effective learning. To develop a thinker's vocabulary, one must become sensitive to words and develop strategies for unlocking the meaning of new words and a process for remembering the new words and their meanings.

\section{Become an Active Reader}

If you are actively involved, physically and mentally, you stay interested and committed. When you become passive, you rapidly lose interest and drift away. To learn from study/reading material, you must be an active, thinking participant in the process, not a passive bystander. Always preview the reading and make sure you have a specific purpose for each assignment. Read actively to fulfil your purpose and answer questions about the material. Keep involved by giving yourself frequent tests over what you've read.

\section{Become an Active Writer}

Writing accurately and express sing the ideas demands not only writing skill but focused attention, critical thinking and active involvement. Only if you become actively involved in the writing process you will be able to communicate your ideas clearly. Writing must have a purpose, a controlling idea or thesis, organized development of idea with major and minor supporting details, and a logical conclusion.

\section{Build Listening \& Note Taking Skills}

Accurately listening to a lecture and deciding what is important are two skills that must be mastered before writing the information. Again, being an active rather than a passive participant is the key to your success. Taking good notes demands that prepare for class, become an active listener, distinguish major from minor points, use a note taking system, participate in class, and review often.

\section{Know How to Study For \& Take Exams}

Preparing for exams will give a better understanding of the material, lower your anxiety, and improve your scores. Find out as much as you can about the exam, study and review the material over a period of time (use the night before as a final review not a cram session), pace yourself during the exam. 


\section{Master Every Course}

True education is not about cramming material. True education is the process of expanding your capabilities, of bringing yourself into the world. Teachers can merely set the stage to create learning through your own actions.

\section{STRATEGIES FOR LEARNING TO LEARN}

Strategies are ways for learners to solve problems encountered in constructing meaning in any context. Unlike skills, strategies chosen by learners are modified to fit the demands of the learning situation. Strategic learners know how and when to alter, modify, combine, and test individual strategies against their prior knowledge, beliefs, and experiences. Strategy teaching does not require commercial materials, nor does it need to be a separate part of the curriculum; it does not consist of "tricks" or isolated activities. Rather, strategic instruction is a process that involves teaching students to read using procedures used by good readers, to write using approaches used by good writers, and to solve problem using techniques used by good problem solvers.

Both research and common sense provide a rationale for using learning strategies with students. There has been a shift in focus for curriculum and instruction based on practical research that has gained attention nationally. Research findings also indicate that the following actions particularly benefit low achieving students:

* Emphasizing meaning and understanding. Teachers who give priority to understanding and meaning help students to comprehend what written text says "between the lines," assist students to communicate in writing thoughts that an audience would care to know, and demonstrate what mathematical procedures mean and how to tackle unfamiliar problems.

* Embedding skills in context. In each subject area, the teacher presents skills within the context of application. Comprehension skills are connected with the text being read, writing skills are a part of the act of composing, and math problems are solved with selected mathematical tools in context.

* Encouraging connections between subject areas and between school and life outside of school. Teachers focus on making connections between subject areas and between what is learned in school and the students' home experiences.

For students to become genuinely strategic, they must participate in authentic learning opportunities that reflect their needs and access their prior knowledge. The learning strategies are organized to engage students in exploring written text, oral text, and illustrations and to extend their understanding and help them expand meaning by making personal connections and sharing learning. Some of the strategies are designed for group work, some are suggested for partners, and some are for individual engagement. Many of the strategies that focus on specific text include suggestions for group involvement before, during, and after the reading of content area materials. Given the social nature of learning, the strategies for expanding meaning include the sharing of personal interpretations through collaborative inquiry.

(c) The International Journal of Indian Psychology, ISSN 2348-5396 (e) | ISSN: 2349-3429 (p) | 107 


\section{Learning to Learn}

The long-term goal of strategic teaching is to help students construct meaning through selfregulated use and adaptation of a wide repertoire of strategies. Teachers are encouraged to reflect and adapt these learning strategies to meet their students' needs as they become strategic learners. The following strategies may be used for learning to learn for optimal results.

\section{A. Exploring Text}

1. Prediction. This is a basic strategy for using prior knowledge to understand text. The learner generates a hypothesis about the type, purpose, or scope of a text to provide a framework for transacting with the text to confirm comprehension. Examples of teaching reading as thinking include prediction, directed reading, and confirming.

2. Brainstorming. Brainstorming is a way to value prior knowledge and prior experience by inviting students to associate concepts with a selected topic. All contributions are accepted and recorded. Group members review and discuss the related ideas and determine how to organize and use the information.

3. Pre Reading Plan (PReP). The Pre Reading Plan is a three-step demonstration for teachers to use before assigning reading to their students. It includes accessing prior knowledge, reflecting on associations, and reformulating knowledge.

4. K-W-L. K-W-L is a strategy that models the active thinking needed when reading expository text. The letters $\mathrm{K}, \mathrm{W}, \mathrm{L}$ stand for three activities students engage in when reading to learn: recalling that they KNOW, determining what they WANT to learn, and identifying what they LEARN as they read.

5. Cloze. Cloze refers to the procedure of using reading material from which words or partial words have been systematically deleted. This procedure has been adapted to serve different purposes. Selected deletion is a way to assess the learner's sense of language and to support prediction and confirmation strategies.

6. Questioning. Questions are tools for engaging attention, investigating ideas, assessing knowledge, and encouraging deeper understanding. Appropriate questions help students develop met cognition and assist them in problem-solving strategies. Teachers use questions to gain information about students' understanding.

7. Think-Along. A think-along is a teaching demonstration that makes the invisible thinking process of reading visible. It is an attempt on the part of the teacher to model the thinking process that any good reader engages in when reading. Students observe as the teacher thinks aloud while reading a text.

8. Big Books. These enlarged texts are designed for shared reading time so that students can be aware of print and how it works. Although the primary purpose is to share the enjoyment of stories or poetry, big books may be used to provide a linguistic framework for language learning within the context of a story or connected text. Predicting and confirming strategies may be used with big books that have predictable patterns and interesting plots.

9. Wordless Books. These are books that tell a story in pictures without words, or sometimes with minimal print. They are valuable resources to encourage language knowledge and usage and 


\section{Learning to Learn}

also to assess oral and written language development. Student responses may include writing a narrative with or without dialogue or creating a script for a play, a puppet show, a radio dramatization, or a video production.

10. Schema Stories. Prior experience with text is helpful in developing a schema for identifying, thinking about, and talking about story structure to encourage comprehension. The experience of arranging parts of a story into a logical sequence assists students in making predictions and confirming language knowledge. The teacher selects short, well structured stories or informational pieces, divides them into sections, and places the parts in an envelope. Groups of students work together to determine the sense or schema of the piece.

\section{B. Expanding Meaning}

1. Semantic Mapping. Visual representations of connected ideas may be labelled as semantic maps, semantic webs, concept maps, clusters, schema diagrams, or structured overviews. After brainstorming and discussing associations on particular topics, students can use semantic mapping to organize the information in categories.

2. Sketch to Stretch. Representing ideas through drawing provides students an alternative way of responding to text. Students may do a listening activity and draw what they visualize, or they may read a text and represent their understanding through illustrations. Sketching may be used to assess students' knowledge of sequential order or main idea and details. Semantic webbing may be used to follow a sketch to stretch activity.

3. Problem Solving. Problem solving is a method of inquiry and is essential as an approach to finding solutions to problems. Development of student capacities for problem solving in all areas of learning is necessary to achieve the goal of helping students become more effective critical thinkers about what they read and hear. The basics of the 21st century include problem solving and communication.

4. Reciprocal Teaching. Reciprocal teaching is an instructional activity that takes place in the form of a dialogue between teachers and students regarding segments of text. The dialogue is structured by the use of four strategies: summarizing, question generating, clarifying, and predicting. The teacher and students take turns assuming the role of teacher in leading this dialogue.

5. Partner Reading. Partner reading encourages the sharing of ideas. Sometimes partners take turns reading aloud, sometimes they each read silently, but they talk about their perceptions, questions, and insights. Partners of different ages and abilities work well together. The teacher may be a student's partner to assess individual needs and strengths.

6. Say Something. This is a reading activity that invites conversation and discussion by partners or small groups of students. Each person receives a text for reading and responding. The participants decide cooperatively how far to read before stopping to talk about the author's ideas. Someone is designated to speak first, or to say something related to the text. Each person listens and responds with comments, reactions, or questions. They may reread the text to clarify understanding or answer questions. 


\section{Learning to Learn}

7. Written Conversation. One sheet of paper is shared by partners as they carry on a silent conversation in writing. Young children can participate by drawing pictures, using invented spelling, or doing both. One person starts the conversation and often asks a question before handing the paper to the writing partner. This conversation continues as the writers respond to each other's comments and questions.

8. Responding to Reading as Writers. This strategy gives readers and writers a sense of authorship by involving students in sharing their writing with peers. The collaboration assists both readers and writers in the composing process as they listen and respond to the written work.

\section{Journals and Logs.}

a. Personal Journals. These journals are like diaries that record personal thoughts, feelings, ideas for exploration, and perplexing questions. The writer and reader are the same person and the contents are not necessarily shared with anyone else.

b. Dialogue Journals. Dialogue journals are another form of written conversation, or two-way responding that may focus on specific needs or issues. The interactive format extends the discussion between a teacher and a student, or between two students, over a period of time to explore understanding and inquiry related to reading, writing, or problem solving.

c. Travelling Journals. When groups of students are working together on a project, book, story, topic, question, or common theme, the individuals write to one another. This strategy is similar to written conversation. The journal may travel from person to person or remain in a central location for individuals to make regular entries. The teacher reads and responds to the group communication.

d. Reading Logs. General reading logs provide opportunities for students to record their thoughts and questions about anything they are reading, including content area or research material. Reading response logs are important components of reading discussion groups in which students share their written responses to initiate and continue discussion about specific text.

e. Learning Logs. These logs are an example of using writing as a way of knowing. They may include responses to a variety of content materials and concepts, or theme cycles, or they may focus on one particular lesson or idea. Students keep track of what they have learned about a particular topic in the learning log and use it for reflection and self-evaluation. Entries may include summaries, insights, and questions to extend learning.

10. Letters. Students need to know that letter writing is an important ability that serves a number of purposes. There are pen pal letters, letters to the editor, letters of application, consumer awareness letters, and friendly letters, notes, invitations, and messages that students may write to real people for real reasons.

11. Authoring Cycle. This is a framework for using the processes of reading and writing throughout the curriculum. Students are engaged in thinking, writing, reading, revising, sharing, editing, and presenting their written work. After choosing a topic, students think about what they want to say and begin a first draft of those ideas. They share, get suggestions from other students, and revise their work. Self-editing is encouraged before an outside editor reviews the work. Multiple drafts are kept in writing folders to monitor progress. 


\section{Learning to Learn}

12. Spelling Strategies. Spelling strategies are ways that students focus on the conventions of written language.

13. Literature Study. Literature discussion groups give students a chance to talk about their perceptions and interpretations of a selected text. After reading the selection and responding in a literature log, they meet to discuss ideas and insights. After discussion, group members decide how far they will read and what they will consider for the next discussion time. Different students serve as discussion leaders.

14. Readers' Theatre. Reading aloud for a collective purpose is a variation of shared reading experiences. Readers' theatre is a group project that gives students the opportunity to work together to present a collaborative oral interpretation of a written text. Rehearsal demonstrates the importance of listening to others and of feeling the rhythm of blended voices. Scripts may be adapted from predictable language stories or those with distinctive dialogue.

15. Text Sets. The text sets used in literature study circles are usually multiple copies of the same text to provide a focus for shared meaning. However, text sets may be a collection of different books on a related topic. Using sets of different texts encourages students to compare, contrast, and make connections in a reading discussion group. Related poetry may be included as text sets as well as different versions of particular fairy tales or collections of books by the same author.

16. Student Research. Reading and writing are important tools in content area learning. Selfselected research promotes active engagement of students in focused study. Many of the questions that students want to research cut across disciplines. A curriculum based on inquiry includes the examination of various perspectives. Students need the opportunity to explore and share their discoveries by presenting their knowledge through various media.

17. Praise-Question-Polish (PQP). PQP is a framework used to assess understanding and evaluate learning. It has three columns for student responses to specific lessons, texts, topics, or focus studies. The praise column is for positive comments, the question column is for recording ideas that are not clear, and the polish column is for suggested changes to improve understanding.

18. Exit Slips. Exit slips are self-evaluations that prompt students to review their learning. They may be used at the end of a class session, the end of a day, the end of a week, or the end of a focused study, a presentation, or a theme unit. Students reflect on what they learned and request further assistance if needed.

\section{BARRIERS TO LEARNING TO LEARN}

The important barriers to learning to learn are a subset of the barriers to learning in general. The most important barriers to students are caused by the unique challenges of learning to learn, including:

\section{Risk adverse students}

Risk-averse students have more difficulty in independent learning because of their discomfort with experimentation which may "fail" in the sense of not giving a correct and final solution 


\section{Learning to Learn}

immediately. Independent learning requires taking initiatives which develop knowledge but not solutions, becoming comfortable with failure and adept at how to use failure to improve.

\section{Discomfort with uncertainty and ambiguity}

Learning is more difficult when conditions, systems and outputs are not constant, when there is no one answers (uncertainty) or when these components are unclear (ambiguity). In response we focus on learning processes more than the products of those processes in evaluating our students work, valuing processes as "better" or "worse" instead of "right" or "wrong" and to respond to student questions with questions to provoke thought and processing instead of providing answers. The tools and learning process model of our strategy assist in providing a framework for ambiguous problems and systems.

\section{Lack of interest in topic}

Uninteresting topics and unrealistic contexts can lead to a lack of commitment to find solutions. We use reports from newspapers and magazines on topics of natural interest to our students (e.g. current events, drugs and love), manual and computer-based management flight simulators and professionally developed business case studies to lure students into the learning space and maintain their interest. For example one system dynamics model attempts to explain the fate of Romeo and Juliet (Radzicki, 19??).

\section{Passive learning model}

Some students prefer a passive learning role in which the instructor or reading material provides the lessons to be mastered or the exact set of steps and tools to apply to get the one right answer. This approach can be efficient for some types of learning and this mode of learning may be the only approach which students have experienced in their formal education. However independent learning requires an active constructivist approach to learning by both the student and instructor. These students need gentle introduction and guidance to a constructivist approach to learning.

\section{Difficulty in reflecting on experience and observation}

Thoughtful reflection and objective self evaluation is essential to independent learning. These skills are difficult to develop and require a degree of confidence which is often incompletely developed in students.

\section{RECOMMENDATIONS}

There are currently significant gaps in engagement with research and continuing professional development of staff in relation to 'what works' and 'what needs to work' in teaching and learning. Both are essential to develop appropriate pedagogy, curricula and successful integration of ICTs for learning to learn. However, strong emphasis has been placed recently on developing effective teaching and learning practice and learner voice - two key features of learning to learn. This is encouraging, and could form a foundation for future research and innovation. In the light of the above discussion the following recommendations are made:

* Government must recognise the importance of effective teaching and learning across all phases of learning in helping individuals of all ages achieve their potential. 


\section{Learning to Learn}

* In the light of the new tasks being assigned to the sector, greater investment in staff development is needed to share good practice and ensure that all staff has the skills to deliver and support learning effectively with the wide variety of learners with whom the sector engages.

* Investment in evidence-based research is also needed, including practitioner research and the development of an expectation that continuing education staff will engage in research and reflective practice, as happens in schools.

* Educationists must be amongst the stakeholders routinely consulted, to identify the research and professional development needs of the continuing education sector.

* The benefits that learning to learn approaches have brought in schools should be promoted to policymakers and to highlight the links between these and existing successful practices. Cooperation, collaboration and coherence should be encouraged across all phases of learning for the benefit of both learners and teachers.

\section{CONCLUSION}

With the increasing complexity of global society, development has become critically dependent on well-trained knowledge workers. That's why we need to prepare our students by teaching them how to learn, tap knowledge and apply such knowledge to problems - either in a global, national or local context. In the future, the adaptive and civilizing role of education needs to be combined in new ways with the developmental, creative, and transformative roles of learning. If education and training is to play its enabling role in supporting transition to the information economy then some strategies must be implemented in certain areas:

1. People - Supplying the skills to drive the information economy. This includes the leaders and workers with the vision and skills to develop and manage new approaches to learning and to implement coordinated and timely change.

2. Infrastructure - Ensuring access at an affordable price to advanced telecommunications and information technology infrastructure including high bandwidth. This includes reliable and sustainable infrastructure support systems within and between education, training and research providers to ensure interoperability.

3. Online content, applications and services - The sector needs to invest in new approaches to education and training content, applications and services which enhance the learning experience in Australia and develop leadership internationally.

4. Policy and organisational framework - Governments need to develop a comprehensive policy framework for education and training, including research and development that supports the information economy and a knowledge society.

If our children are to grow up to make important contributions to our society, it is essential that we provide them with powerful tools and experiences across the curriculum. This will require a new culture of teaching and learning that engages students as contributors. (November, 2008) 


\section{Learning to Learn}

\section{Acknowledgments}

The author appreciates all those who participated in the study and helped to facilitate the research process.

\section{Conflict of Interests}

The author declared no conflict of interests.

\section{REFERENCES}

Anderson, T. et al. (2001), "Peer interaction and the learning of critical thinking skills in Further Education students,” Instructional Science 29 (1), 1-32.

Armatas, C. (2003), "Impacts of an online supported, resource based learning environment: does one size fit all?” Distance Education, 24 (2), 141-58.

Baumfield, et al. (in press), "Catalytic tools: understanding the interaction of enquiry and feedback in teachers' learning," European Journal of Teacher Education.

Claxton, G. and Lucas, B. (2008), "School as a foundation for lifelong learning: The implications of a lifelong learning perspective for the re-imagining of school age education," Unpublished paper for the Inquiry into the Future of Lifelong Learning.

Coffield, F. (2008), “Just suppose teaching and learning became the first priority,” London: Learning and Skills Network.

Coffield, F. et al. (2004), "Learning styles and pedagogy in post-16 learning: a systematic and critical review,” London: Learning and Skills Research Centre.

Coffield, F. et al. (2004), "Should we be using learning styles? What research has to say to practice,” London: Learning and Skills Research Centre.

Cornford, I.R. (2002), “Learning-to-learn as a basis for effective lifelong learning,” International Journal of Lifelong Education, 21 (4), 357-368.

Coutinho, S.A. (2006), “The Relationship between the Need for Cognition, Metacognition, and Intellectual Task Performance,” Educational Research and Reviews, 1 (5), 162-164.

Donovan, M.S. et al. (1999), “How people learn: bridging research and practice,” National Research Council.

European Commission (2005), "Proposal for a Recommendation of the European Parliament and of the Council on key competences for lifelong learning,” European commission, Brussels.

Hall, E. and Moseley, D. (2005), "Is there a role for learning styles in personalised education and training?” International Journal of Lifelong Education, 24 (3), 243-255.

Hautamäki et al. (2002), “Assessing Learning-to-Learn: A Framework,” Helsinki: Centre for Educational Assessment, Helsinki University / National Board of Education.

Knapper, J. and Cropley, A.C. (2000), “Lifelong Learning in Higher Education (Third edition),” Routledge.

Lucas, B. and Greany, T. (2000), "Learning to learn: setting the agenda for schools in the 21st century,” Network Education Press. 


\section{Learning to Learn}

Lucas, B. et al. (2003), “Teaching pupils how to learn,” Network Education Press.

Noushad, P.P. (2008), "Cognitions about cognitions: the theory of metacognition,” Farook Training College, Kerala, India. Available online at: http://www.eric.ed.gov/ ERICDocs/data/ericdocs2sql/content_storage_01/0000019b/80/3e/70/36.pdf

Palinscar, A.S., \& Brown, A.L. (1985), "Reciprocal teaching: Activities to promote reading with your mind,” In T.L. Harris \& E.J. Cogen (Eds.), Reading, thinking, and concept development: Strategies for the classroom. New York: The College Board.

Pressley, M. et al. (1989), “The challenges of classroom strategy instruction,” The Elementary School Journal, 89(3), 301-335.

Thompson, R. (2009), "Creativity, knowledge and curriculum in Further Education: a Bernsteinian perspective," British Journal of Educational Studies, 57 (1), 37-54.

Tierney, R.J. et al. (1990), "Reading strategies and practices-A compendium (3rd ed.),". Boston: Allyn Bacon.

How to cite this article: N Anjum (2016), Learning to Learn, International Journal of Indian Psychology, Volume 4, Issue 1, No. 79, ISSN:2348-5396 (e), ISSN:2349-3429 (p), DIP:18.01.091/20160304, ISBN:978-1-365-56745-2 